\title{
Impact of Self-Regulation Methods on the Psycho-Emotional State of Future Teachers
}

\author{
Lyudmila N. Voloshina*, Elena A. Arseenko, Karina E. Panasenko, \\ Kira K. Stebunova, Andrey A. Tretyakov \\ Belgorod State University, Russia
}

Received July 22, 2019; Revised September 20, 2019; Accepted September 30, 2019

Copyright $\bigcirc 2019$ by authors, all rights reserved. Authors agree that this article remains permanently open access under the terms of the Creative Commons Attribution License 4.0 International License

\begin{abstract}
The authors remark the necessity to develop the psycho-emotional self-assessment and self-regulation capability of future teachers during the period of vocational training at the university. The training program on the development of students' psycho-emotional self-regulation is presented. The possibility of training practice on behavior and activity self-regulation development as one of the phenomena of a person's mental life is investigated via methods of questioning, operational control of neuropsychic activity (electrocutaneous resistance), and the Luscher test. This training has been examined on students of various fields of education at a pedagogical university, and has shown the effectiveness in the awareness of future teachers of its importance to the development of resistance against stressful situations and in the direction of developing the ability of self-regulation of one's psycho-emotional state in teaching.
\end{abstract}

Keywords Psycho-Emotional State, Students, Teachers, Self-Regulation, Vocational Training, Teaching

\section{Introduction}

Modern teaching and educative activities are associated with increasing psycho-emotional stress. Dynamic variations in the education system make it impossible for teachers to adapt, to comprehend innovations critically, and to acquire valuable experience. Consequently, it leads to the deterioration of health and also decreased functioning. Investigations on the physical and mental health of teachers, as a professional group, indicate the presence of emotional fatigue and mental exhaustion over half of the respondents, and also neurological disorders in $41 \%$ of cases. Indifference, apathy, and rigidity are experienced by $12 \%$ of teachers [Mongush, 2015; Sazonov, 2012].

The adverse psycho-emotional state of teachers can impact the health of children negatively following many domestic and foreign authors [Gorelikov, 2016; Dorado et al. 2016]. According to the experiences in European countries, teacher's psycho-emotional state is required to be tested regularly [Greene and Schunk, 2017; Schmidt and Finan, 2018]. In several studies, inadequate techniques and programs are present for personal psychotherapy and health preservation represented in the content of future teacher education [Morosanova, et al. 2017; Zobnina and Kislyakova, 2018; Zeighami and Bahmaei, 2016].

The presence of high-level psycho-emotional stress in teaching commence the task to train teachers to use effective methods of self-diagnostics and self-regulation at pedagogical universities, which allows relieving fatigue, avoiding overwork, feeling well, boosting activity, and managing their emotional state.

It is believed that this behavior strategy which is capable of contributing to the successful adaptation of the aspiring teacher, provide a full-fledged professional and social activity in the long term and also assist in avoiding problems of early professional burnout.

The impact of self-regulation methods on the psycho-emotional state of university students during vocational training is evaluated.

\section{Material and Methods}

A set of methods was employed in accordance with the purpose of the study: theoretical (analytical-synthesizing, and comparative), empirical (pedagogical experiment, questioning, method of neuropsychic activity operational control - electrocutaneous resistance (ECR), and Luscher test), and also methods of mathematical data processing.

\section{Results and Discussion}

The significant role of self-regulation of the 
psycho-emotional state in teaching activity aims higher educational institutions to develop this capacity at the stage of professional training. The incapacity to control oneself and lack of knowledge in self-regulation techniques lead to negative traits fixed in the personality structure, which cause to destroying the health [Mongush, 2015; Gorelikov, 2016; Sukhoviienko, 2017]. The ability of teachers to self-regulate the states, actions, and efficiency is an essential indicator of their professional competence. In the analyzed studies, psycho-emotional self-regulation is regarded as a systemic, integral, professionally outstanding quality of teachers and involves the ability to establish correspondence between the requirements of teaching activity, psycho-emotional states of a person, and their performances in particular circumstances [Odintsova and Zakharova, 2017; Latygovskaya, 2017; Morosanova, et al. 2017].

An empirical study was carried out for two months (8 weeks) at the department of preschool, primary and special education (pedagogical institute, Belgorod State University) to evaluate the impact of self-regulating methods on the psycho-emotional state of future teachers. Fifty-four graduate students participated in the experimental study, and also 54 students were arranged in the control group to neutralize the effect of time on research.

The demographic data of the two control and experimental groups are listed in Table 1 below:

Table 1. Demographic Information

\begin{tabular}{|c|c|c|c|}
\hline \multicolumn{2}{|c|}{} & Experimental & Control \\
\hline \multirow{4}{*}{ Age } & $18-20$ & 18 & 15 \\
\cline { 2 - 4 } & $20-22$ & 20 & 19 \\
\cline { 2 - 4 } & $22-24$ & 16 & 20 \\
\hline \multirow{4}{*}{$\begin{array}{c}\text { University } \\
\text { Course }\end{array}$} & Educational Science & 19 & 21 \\
\cline { 2 - 4 } & Academic advice & 18 & 16 \\
\cline { 2 - 4 } & $\begin{array}{c}\text { Academic } \\
\text { Management }\end{array}$ & 17 & 17 \\
\hline
\end{tabular}

The experimental plan included a focused work on teaching students in methods of diagnosis and self-regulation and implementing the given methods into the educational activity; however, no training programs were used for the control group.

The algorithm for Experimental Group implementation included:

Stage 1 - diagnostics $-1^{\text {st }}$ week;

Stage 2 - training $-2-6^{\text {th }}$ week;

Stage 3 - developing $-7^{\text {th }}$ week;

Stage $4-$ control $-8^{\text {th }}$ week.

At the first stage, diagnostics of the psycho-physiological state of students throughout the educational activity was conducted. During the first week, the psycho-physiological state of the future teachers was investigated according to the tests as mentioned earlier. Dynamics of the neuro-psychic activity level were reported based on the ECR indicators (before classes, after 1, 2, 3 double classes).

At the second stage $\left(2-6^{\text {th }}\right.$ week $)$, future teachers were trained in self-regulation methods influencing their psycho-emotional state.

Methods of self-regulation were picked from those described in the literature [Odintsova and Zakharova, 2017; Stavitsky, 1993], and modified by the authors considering the age features. The training of future teachers in the psycho-emotional self-regulation methods was performed based on the developed algorithm throughout an educational activity by employing progressive muscular relaxation by E. Jacobson, autogenic training, mental training, and psychoregulation pauses with the restorative component.

The training commenced with the most available self-regulation method - E. Jacobson's progressive muscular relaxation, which they mastered during the $2^{\text {nd }}$ week.

In the third week, the apprentices mastered autogenic training (AT).

The fourth and fifth weeks were devoted to teaching mental training.

\section{$4^{\text {th }}$ week:}

- Monday-Wednesday - training of muscular relaxation (I) (after three double classes within 10 minutes);

- $\quad$ Thursday-Friday - training of muscular relaxation (II) (short program - after three double classes within 8 minutes).

$5^{\text {th }}$ week:

- $\quad$ Tuesday-Wednesday - training of mental relaxation (I) (after three double classes within 10 minutes);

- $\quad$ Thursday-Friday - training of mental relaxation (II) (short program - after three double classes within 7 minutes).

The sixth week is dedicated to teaching psycho-regulation pause with the restorative component (after three double classes within 5 minutes).

Training in these methods was conducted during five weeks from $2^{\text {nd }}$ to ${ }^{\text {sixth }}$ weeks after 20 -minute classes. The time period was reduced to 5-7 minutes while mastering these methods

The effectiveness of self-regulation methods was estimated by the objective method of neuro-psychic activity operational control, in following the ECR measurement, which was performed at the end of the training week before and after its implementation.

After completing the course of study and throughout the $7^{\text {th }}-8^{\text {th }}$ week, the self-regulation methods were introduced into the educational activities of university and conducted directly in classrooms before (a psych regulation pause with a restorative component within 5 minutes) and after classes (mental training - mental relaxation training (II) (short program within 7 minutes). 
Table 2. Evaluation of subjective and objective indicators of the NPA level of future teachers, score; Experimental Group

\begin{tabular}{|c|c|c|c|c|c|}
\hline \multicolumn{2}{|c|}{ Before the experiment } & \multirow{3}{*}{$\mathrm{P}$} & \multicolumn{2}{|c|}{ After the experiment } & \multirow{3}{*}{$\mathrm{P}$} \\
\hline $\begin{array}{l}\text { Subjective evaluation } \\
\text { (score) }\end{array}$ & $\begin{array}{c}\text { Objective evaluation } \\
\text { (score) }\end{array}$ & & $\begin{array}{c}\text { Subjective evaluation } \\
\text { (score) }\end{array}$ & $\begin{array}{c}\text { Objective evaluation } \\
\text { (score) }\end{array}$ & \\
\hline $\mathrm{X}_{1} \pm \mathrm{m}_{1}$ & $\mathrm{X}_{2} \pm \mathrm{m}_{2}$ & & $\mathrm{X}_{3} \pm \mathrm{m}_{3}$ & $\mathrm{X}_{4} \pm \mathrm{m}_{4}$ & \\
\hline $3.8 \pm 0.26$ & $4.7 \pm 0.34$ & $<0.05$ & $3.6 \pm 0.22$ & $3.9 \pm 0.23$ & \\
\hline
\end{tabular}

Table 3. Evaluation of subjective and objective indicators of the NPA level of future teachers, score; Control Group

\begin{tabular}{|c|c|c|c|c|}
\hline \multicolumn{2}{|c|}{ Pre-Test } & \multicolumn{2}{|c|}{ Post-Test } \\
$\begin{array}{c}\text { Subjective evaluation } \\
\text { (score) }\end{array}$ & $\begin{array}{c}\text { Objective evaluation } \\
\text { (score) }\end{array}$ & $\mathrm{P}$ & $\begin{array}{c}\text { Subjective evaluation } \\
\text { (score) }\end{array}$ & $\begin{array}{c}\text { Objective evaluation } \\
\text { (score) }\end{array}$ \\
\hline $\mathrm{X}_{1} \pm \mathrm{m}_{1}$ & $\mathrm{X}_{2} \pm \mathrm{m}_{2}$ & $\mathrm{X}_{3} \pm \mathrm{m}_{3}$ & $\mathrm{X}_{4} \pm \mathrm{m}_{4}$ \\
\hline $3.3 \pm 0.18$ & $3.9 \pm 0.28$ & $>0.05$ & $3.2 \pm 0.16$ & $3.8 \pm 0.21$ \\
\hline
\end{tabular}

The subjective and objective assessments were applied to evaluate the neuro-psychic activity level of future teachers at the beginning and end of the investigation before the classes. The subjective assessment was carried out using the survey method and the Luscher test.

An objective assessment of the neuro-psychic activity level of future teachers was identified by the ECR measuring method, which reflects an objective view of the studied states.

The subjective and objective assessments of mental performance were categorized into six levels and converted into points on a scale from one to six, which enabled the authors to process the outcomes statistically and assess the state of neuro-psychic activity (NPA) of future teachers objectively at the beginning and the end of the research (Table 1).It is indicated that the students' self-assessment of their neuro-psychic activity level is insignificant to objective indicators before the experiment, comparing the scores of self-assessments and the scores of ECR objective indicators, and according to Table 1. The discrepancy between the subjective and objective scores in points before the experiment is reliable $(\mathrm{P}<0.05)$.

Insignificancy of self-assessment of the neuro-psychic activity level suggests that future teachers possess low self-esteem at the beginning of the investigation, which is expressed in self-rejection, and self-denial of their abilities. This issue leads to the neuroticism of future teachers and imposes a negative imprint on educational effectiveness.

The importance of self-esteem in educational activities for the subjective determination of the neuro-psychic activity level can hardly be overestimated. The ability of future teachers to analyze alterations in their state of health, the neuro-psychic activity level and the enthusiasm to create an optimal level of mental state, and also employing self-regulation methods to obtain the intended purpose, are essential factors promoting the increase of professional efficiency.

Comparing the scores of objective ECR indicators and self-assessment scores (considering the data from Table 1), it has been observed that the subjective assessment of the NPA level between future teachers approached to the objective $(3.6 \pm 0.22$ points and $3.9 \pm 0.23$ points, respectively) at the end of the study, where the self-regulation methods were applied to optimize the mental state. The discrepancies between the subjective and objective scores of 0.3 points $(\mathrm{P}<0.05)$ are unreliable, which suggests that after training and direct application of self-regulation methods throughout the educational activity, the subjective assessment is almost reached to objective value. The students have mastered the self-assessment methods and started to evaluate their mental state.

This analysis was also performed for the control group to neutralize the effect of time, the results of which are presented in Table 3.

It is indicated that the students' self-assessment of their neuro-psychic activity level is not insignificant to objective indicators before the experiment, comparing the scores of self-assessments and the scores of ECR objective indicators for the control group, and according to Table 3 . The discrepancy between the subjective and objective scores in points before the experiments is not reliable ( $\mathrm{P}>$ $0.05)$.

The results of the analysis revealed that according to the ECR indicators, the initial state of the NPA of future teachers before the implementation of progressive muscular relaxation by E. Jacobson, is at the medium level $-21.4 \pm 2.57 \mathrm{kOhm}$ (Table 4). 
Table 4. Dynamics of ECR indicators in the training of future teachers in self-regulation methods, kOhm for Experimental Group

\begin{tabular}{|c|c|c|c|c|c|}
\hline \multirow{2}{*}{$\begin{array}{c}\text { № } \\
\text { ПП }\end{array}$} & Self-regulation methods & before the experiment & After experiment & \multirow{2}{*}{ Differential } & \multirow{2}{*}{ P } \\
\cline { 3 - 4 } & & $\mathrm{X} 1 \pm \mathrm{m} 1$ & $\mathrm{X} 2 \pm \mathrm{m} 2$ & & \\
\hline 1. & Progressive muscular relaxation by E. Jacobson & $21.4 \pm 2.57$ & $27.5 \pm 2.4$ & 6.1 & $>0.05$ \\
\hline 2. & Autogenic training & $22.2 \pm 1.98$ & $29.4 \pm 2.1$ & 7.2 & $>0.05$ \\
\hline 3. & Mental training & $25.4 \pm 2.39$ & $37.2 \pm 2.04$ & 11.8 & $<0.01$ \\
\hline 4. & Psycho-regulation pauses with a restorative component & $24.3 \pm 1.98$ & $33.1 \pm 1.94$ & 8.8 & $<0.05$ \\
\hline
\end{tabular}

Table 5. Dynamics of ECR indicators in the training of future teachers in self-regulation methods, kOhm For Control Group

\begin{tabular}{|c|c|c|c|c|c|}
\hline \multirow{2}{*}{$\begin{array}{l}\text { № } \\
\text { ПП }\end{array}$} & \multirow{2}{*}{ Self-regulation methods } & Pre-Test & Post-Test & \multirow{2}{*}{ Differential } & \multirow{2}{*}{$\mathrm{P}$} \\
\hline & & $\mathrm{X}_{1} \pm \mathrm{m}_{1}$ & $\mathrm{X}_{2} \pm \mathrm{m}_{2}$ & & \\
\hline 1. & Progressive muscular relaxation by E. Jacobson & $19.52 \pm 1.76$ & $20.1 \pm 2.8$ & 0.58 & $>0.05$ \\
\hline 2. & Autogenic training & $18.28 \pm 2.06$ & $17.9 \pm 1.99$ & 0.38 & $>0.05$ \\
\hline 3. & Mental training & $26.2 \pm 1.93$ & $27.1 \pm 1.48$ & 0.9 & $>0.05$ \\
\hline 4. & Psycho-regulation pauses with a restorative component & $23.74 \pm 1.26$ & $24.2 \pm 2.65$ & 0.46 & $>0.05$ \\
\hline
\end{tabular}

The ECR indicators decrease by $6.1 \mathrm{kOhm}$ to $27.5 \pm 2.4$ $\mathrm{kOhm}$ after training; however, this reduction is not significant. Despite a slight decrease in neuro-psychic activity after training progressive muscular relaxation, E. Jacobson's method is the most accessible and exciting for students as a result of its simplicity to implement [2, 16-18]. Furthermore, training in straining and relaxation of muscle groups in the whole range of their activity - from tension to complete relaxation - assist in improving the mental regulation of muscle work and in normalizing one's emotional state [Sannikova and Nabiullina, 2015; Hwang et al. 2017; [Zhampeisov, et al 2018]. It should be mentioned that the motor and mental control of muscle activity allow trainees to memorize the sensations that they associate with certain degrees of muscle activity up to their complete relaxation, and understand that muscles not involving in the work should be relaxed. The issue, as mentioned above, creates conditions for further training in self-regulation methods. The results of previous researches also support these outcomes [Borzykh and Arseenko, 2012; Koivuniemi et al. 2017; Salzer and Roczen, 2018; Valtonenm et al. 2016; [Lee, Y., et al 2018].

While teaching autogenic training (AT) to future teachers, it was found that their neuro-psychic activity decreased by $7.2 \mathrm{kOhm}$ - to $29.4 \pm 2.1 \mathrm{kOhm}$; however, this reduction did not yet lead their state to the optimum level, i. e. up to the state of predisposition to perform any activity $-31-60 \mathrm{kOhm}$. This issue was seemingly due to the fact that students have significant challenges in achieving internal concentration, focusing on feelings, images, ideas, and sensations, which led to excessive muscle strain and made impossible to complete relaxation and exiting out of this state.

The results of students' mental training indicated a noticeable trend of alterations in the ECR indicators (11.8 $\mathrm{kOhm}$ ), which cannot be observed when the two previously mentioned methods are applied. ECR indicators decreased significantly and reliably and reached the optimal level of NPA - below the average $-37.2 \pm 2.04 \mathrm{kOhm}(\mathrm{P}<0.01)$. This shift in NPA reduction implies that after training the two previous methods of self-regulation (progressive muscular relaxation by E. Jacobson and AT), mental training affects significantly and gets additional strength. It turns to a type of trigger mechanism for decreasing the NPA level. All this provides grounds for the authors to declare that mental training affects the reduction of neuro-psychic strain significantly.

Training the psycho-regulation pause with the restorative component also diminishes the NPA reliably, although the recovery effect is slightly lower: $33.1 \pm 1.94$ $\mathrm{kOhm}(\mathrm{P}<0.05)$ compared to the mental training $-37.2 \pm$ $2.04 \mathrm{kOhm}(\mathrm{P}<0.01)$.

After completing the course of study, methods of self-regulation have been implemented for two weeks in the educational activity of future teachers as its integral part. The classes were held to improve the skills of utilizing self-regulation methods:

- Before classes, there took place a psycho-regulation pause with a restorative component (within 5 minutes);

- After classes - mental training and mental relaxation training (II) (a short program within 7 minutes).

In the $8^{\text {th }}$ week, monitoring and evaluation of the success of teaching in self-regulation methods and their application in the process of educational activity were performed.

This analysis was also performed for the control group to neutralize the effect of time, the results of which are presented in Table 5. 


\section{Conclusions}

In conclusion, it can be declared that future teachers successfully master self-regulation methods such as E. Jacobson's muscular relaxation, autogenic training, mental training, and psych regulation pauses with the restorative component. These methods affect the neuro-psychic activity regulation positively. Mental training and psycho-regulation pause with the restorative component occurred to be more rational forms of self-regulation throughout the work with students. Subsequently, they have been involved in educational activities.

After practicing each method of self-regulation, students subjectively noted improvements in health, mood, and emotional recovery. However, it can be concluded from objective indicators that the highest impact is achieved when mental training was performed to optimize neuro-psychic activity. According to subjective rating, this option was also preferred by all students as the most acceptable, effective, and affordable option.

On the analysis of experimental data, it was found that students have mastered self-regulation methods within a period of five weeks. Consequently, the approximate time threshold for their acquirement was determined. The results of control investigations confirmed that students have fully mastered the self-regulation methods of the psycho-emotional state in the course of educational activity and apply them in the process of educational activity quite successfully.

It is believed that the ability to self-diagnosis and self-regulation would optimize the psycho-emotional state of teachers in the process of professional activity, and also increase their mental and physical abilities.

\section{REFERENCES}

[1] Bakhtiar, A., Webster, E. A., \& Hadwin, A. F. (2018). Regulation and socio-emotional interactions in a positive and a negative group climate. Metacognition and Learning, 13(1), 57-90.

[2] Borzykh, I. S., \& Arseenko, E. A. (2012). Optimization of students' mental state in the process of educational activities using mental training. In: Bulletin of the Students Scientific Society: a collection of student scientific articles of students of the "School of the young researcher"; National Research University "BelSU", 130-134. (In Russian).

[3] Dorado, J. S., Martinez, M., McArthur, L. E., \& Leibovitz, T. (2016). Healthy environments and response to trauma in schools (hearts): A whole-school, multi-level, prevention and intervention program for creating trauma-informed, safe and supportive schools. School Mental Health, 8(1), 163-176. DOI: $10.1007 / \mathrm{s} 12310-016-9177-0$

[4] Engin, M. (2017). Contributions and silence in academic talk: Exploring learner experiences of dialogic interaction.
Learning, Culture and Social Interaction, 12, 78-86.

[5] Gorelikov, S. Y. (2016). Professional burnout and the legal behavior of a preschool teacher. The world of science, 4(3), 21.

[6] Greene, J. A., \& Schunk, D. H. (2017). Historical, Contemporary, and Future Perspectives on Self-Regulated Learning and Performance. In: Handbook of Self-Regulation of Learning and Performance (pp. 17-32). Routledge.

[7] Hwang, Y., Bartlett, B., Greben, M., \& Hand, K. (2017). A systematic review of mindfulness interventions for in-service teachers: A tool to enhance teacher wellbeing and performance. Teaching and Teacher Education, 64, 26-42. DOI: http://dx.doi.org/10.1016/j.tate.2017.01.015

[8] Jacobson, E. (1938). Progressive relaxation. Chicago: University of Chicago Press.

[9] Jennings, P. A., Brown, J. L., Frank, J. L., Doyle, S., Oh, Y., Davis, R., \& Greenberg, M. T. (2017). Impacts of the CARE for teachers' program on teachers' social and emotional competence and classroom interactions. Journal of Educational Psychology, 109(7), 1010-1028. DOI: 10.1037/EDU0000187

[10] Koivuniemi, M., Panadero, E., Malmberg, J., \& Jarvela, S. (2017). Higher education students' learning challenges and regulatory skills in different learning situations / DesafHos de aprendizaje y habilidades de regulaciyn en distintas situaciones de aprendizaje en estudiantes de educaciyn superior. Infancia Y Aprendizaje, 40(1), 19-55.

[11] Kurochkina, I. A. (2018) Competitiveness of a teacher of preschool educational organizations. In: Acmeology of vocational education (Proceedings of the 14th International Scientific Practical Conference). pp. 234-237.

[12] Latygovskaya, O.V. (2017). Valeologic competence of preschool education teacher as a prerequisite for the formation of health culture for children of primary preschool age. In: Modernization of vocational and pedagogical education: trends, strategy, international experience (International scientific conference proceedings). Edited by M.P. Tyrina, L.G. Kulikova. 203-207. (In Russian)

[13] Lee, Y., Capraro, R. M., \& Capraro, M. M. (2018). Mathematics Teachers' Subject Matter Knowledge and Pedagogical Content Knowledge in Problem Posing. International Electronic Journal of Mathematics Education, 13(2), 75-90. https://doi.org/10.12973/iejme/2698

[14] Maryeyeva, T. V. (2017). Pre-school educational institution teachers' professional image and its structure. In: Scientific look into the future, $3(6), 10-19$.

[15] Mongush, O. O. (2015). Emotional burnout in the professional activities of teachers of preschool educational institutions. In: Actual issues of modern pedagogy (Proceedings of the VII International Scientific Conference), 47-51.

[16] Morosanova, V. I., Fomina, T. G., \& Tsyganov, I. Y. (2017). Conscious self-regulation and attitude to learning in achieving learning goals: monograph. Russ. Acad. Education, Institute of Psychology. Saint-Petersburg, Nestor History, $376 \mathrm{p}$. 
[17] Odintsova, M. A., \& Zakharova, N. L. (2017) Psychology of stress: a textbook and a workshop for academic undergraduate. Moscow, Yurayt, 299 p. (In Russian).

[18] Salzer, C., \& Roczen, N. (2018). Assessing global competence in PISA 2018: Challenges and approaches to capturing a complex construct. International Journal of Development Education and Global Learning, 10 (1), 5-20. DOI: https://doi.org/10.18546/IJDEGL.10.1.02

[19] Sannikova, L. N., \& Nabiullina, A. A. (2015). Prevention and correction of professional burnout of pre-school teachers. In: The world of childhood and education. Proceedings of the IX internally-correspondence All-Russian scientific-practical conference with the invitation of representatives of the CIS countries (Magnitogorsk), 124-128.(In Russian).

[20] Sazonov, N. P. (2012). Self-regulation as a way to prevent professional burnout of a preschool teacher. The world of science, culture, education (Gorno-Altaisk), 1(32), 162-164. (In Russian).

[21] Schmidt, A. F., \& Finan, C. (2018). Linear regression and the normality assumption. Journal of Clinical Epidemiology, 98, 146-151. DOI: 10.1016/J.JCLINEPI.2017.12.006

[22] Stavitsky, K. R. (1993). Use of psychoregulation in the preparation of sports teams. Theory and practice of physical culture, 2, 30-33. (In Russian).

[23] Sukhoviienko, N. (2017). Theoretical and methodological principles of professional preparatory training in inclusive pre-school education. Paradigm of Knowledge, 5(25), 92-112.

[24] Valtonen, T., Sointu, E., Kukkonen, J., Hakkinen, P., Jarvela, S., Ahonen, A., Naykki, P., Paysa-Tarhonen, J. \& Makitalo-Siegl, K. (2016). Insights into Finnish first-year preservice teachers' twenty-first century skills. Education and Information Technologies, 1- 15.

[25] Vedishenkova, M. V. (2016). The development of parents pedagogical competence in pre-school science education institution. International Journal of Environmental and Science Education, 11(3), 107-117.

[26] Zobnina, T. V., Kislyakova, L. P. (2018). Study of the relationship between conscious self-regulation of voluntary activity and the level of subjective control among students future teachers. Current research on social issues, 9(4), 88-102.

[27] Zhampeisov, K., Balykbayev, T., Kolumbayeva, N. K. S., \& Aitpayeva, A. (2018). National Component of the Training Content of the Teachers in Kazakhstan's school. Opción, 34(85-2), 653-677.

[28] Zeighami, N., \& Bahmaei, R. (2016). Sociological study of structural and capital factors affecting the healthoriented lifestyle of over 15 year old citizens in Shiraz. UCT Journal of Social Sciences and Humanities Research, 4(3), 5-15. 